\title{
The effect of ONCE Renal on minerals and electrolytes in predialysis patients with chronic kidney disease
}

\author{
Bancha Satirapoj' \\ Janjira Prapakorn² \\ Dollapas Punpanich ${ }^{2}$ \\ Chantima Pongsuparbchon ${ }^{3}$ \\ Ouppatham Supasyndh' \\ 'Division of Nephrology, Department \\ of Medicine, ${ }^{2}$ Research Unit, \\ Department of Medicine, ${ }^{3} \mathrm{Clinical}$ \\ Research Center, Phramongkutklao \\ Hospital, Phramongkutklao College of \\ Medicine, Bangkok, Thailand
}

This article was published in the following Dove Press journal: International Journal of Nephrology and Renovascular Disease 5 April 2016

Number of times this article has been viewed

Background: Malnutrition is one common adverse consequence in patients with advanced chronic kidney disease (CKD), and most patients have a lower-than-normal dietary energy intake. The present study was undertaken to examine whether orally administered ONCE Renal formula (ORF) supplement would improve energy intake without minerals and electrolytes disturbances in predialysis patients with CKD.

Methods: All eligible nondiabetic patients with CKD received ORF supplement for 1 week. Nutrition markers, renal function, and minerals and electrolytes were evaluated before and after supplementing. All patients kept a 3-day food record and were interviewed by a registered dietitian.

Results: A total of 29 patients with mean age $64.9 \pm 13.3$ years were included. Mean estimated glomerular filtration rate was $37.7 \pm 12.1 \mathrm{~mL} / \mathrm{min} / 1.73 \mathrm{~m}^{2}$. A significant increase was observed in amount of energy, fat, fiber, calcium, and magnesium intake after 1 week of ORF supplement. Moreover, in comparison with baseline values, the patients displayed decreased dietary protein intake and blood urea nitrogen and increased serum magnesium. However, no significant change was found in renal function, nutritional markers (body weight, prealbumin, albumin, and protein equivalence of total nitrogen appearance), serum calcium, phosphorus, sodium, potassium, and bicarbonate.

Conclusion: In patients with CKD, ingestion of ORF was well tolerated and had a positive effect with an increase in dietary energy, fat, and fiber intake, as well as a decreased dietary protein intake. No mineral or electrolyte abnormalities were observed during the study.

Keywords: oral-specific renal nutrition, malnutrition, chronic kidney disease

\section{Background}

Protein energy wasting (PEW) and inflammation are common adverse consequences of advanced chronic kidney disease (CKD) and are associated with impaired quality of life and increased morbidity and mortality. ${ }^{1}$ Several studies have indicated a prevalence of this condition ranging from $20 \%$ to $30 \%$ and increasing in line with CKD progression..$^{2-4}$ In contrast, advanced CKD patients often intake excessive amounts of various nutrients, including protein, sodium, phosphorus, and potassium, that have been associated with increased uremic complications and mortality. These problems can be limited by carefully controlling the composition of the dietary intake. ${ }^{5}$ Therefore, oralspecific renal nutritional supplementation might be one therapeutic intervention for these patients. Therapies designed to increase energy and fiber intake without protein loading and electrolyte disturbances in CKD patients might, therefore, be expected to improve their quality of life, and possibly their survival. 
CKD is becoming more common due to the rising incidence of diabetes, hypertension, and obesity. ${ }^{6}$ Optimal predialysis CKD management can improve morbidity, mortality, dialysis, and transplantation outcome. ${ }^{7}$ Applying the various dietary interventions to achieve therapeutic goals in a CKD population would have a beneficial effect on outcomes, including the slowing of the progression of CKD and the treatment of protein energy wasting. ${ }^{5}$ The implementation of dietary interventions can be challenging to the health care team and patients. Most advanced CKD and hemodialysis patients have a lower-than-normal dietary energy intake, and oral nutrition supplements are further needed to achieve intake recommendations. ${ }^{8,9}$ Currently, no consensus guidelines exist on the type, time of initiation, or duration of oral nutrition supplements. ${ }^{10}$ The present study was undertaken to examine whether orally administered dietary renal-specific formula or ONCE Renal formula (ORF: Thai Otsuka Phramaceutical Co., Ltd., Bangrak, Thailand) supplement that provides more energy, fiber, and trace elements intake, and less protein intake could improve energy intake and maintain nutrition status and electrolyte balance among CKD patients. The purpose of the present study was to assess the impact of an ORF supplement on the nutritional status and minerals and electrolytes of predialysis CKD patients.

\section{Methods}

This trial was a prospective interventional study in patients with CKD stage III-IV. This study was approved by the Institution Review Board, Royal Thai Army Medical Department, and all subjects participated in the study after giving informed consent. Inclusion criteria of the study included age 18 years or older with CKD stage III or IV, stable renal function or $<10 \%$ change in glomerular filtration rate (GFR) within 3 months, and no change in any medical treatment within 3 months before starting the study. Exclusion criteria included diabetes mellitus, active malignancy, severe heart, lung, or liver disease, stroke, chronic infection within 1 year of starting the study, and malnourished conditions defined as a loss of $\geq 5 \%$ body weight over the past 3 months and serum albumin concentration $<3.5 \mathrm{~g} / \mathrm{dL}$.

All patients were assigned to ingest ORF for 1 week. The intervention consisted of an orally liquid ORF supplementation instead of $30 \%$ of daily total caloric intake of CKD patients. Each serving of ORF preparation consisted of $360 \mathrm{kcal}$ per $76 \mathrm{~g}$ and the following ingredients: $7.19 \mathrm{~g}$ of proteins, $48.25 \mathrm{~g}$ of carbohydrate with fiber $2.99 \mathrm{~g}, 15.95 \mathrm{~g}$ of fat, $143.6 \mathrm{mg}$ of calcium, $143.6 \mathrm{mg}$ of phosphorus, $197.4 \mathrm{mg}$
Table I ONCE Renal formula

\begin{tabular}{|c|c|}
\hline Macronutrient & $\begin{array}{l}\text { One serving or } 76 \mathrm{~g} \\
(360 \mathrm{kcal})\end{array}$ \\
\hline \multicolumn{2}{|c|}{ Caloric distribution of macronutrients (\%) } \\
\hline Protein & $8 \%$ \\
\hline Carbohydrate & $52 \%$ \\
\hline Fat & $40 \%$ \\
\hline \multicolumn{2}{|l|}{ Source } \\
\hline Protein & $7.19 \mathrm{~g}$ \\
\hline Casein & $3.595(50 \%)$ \\
\hline Soy protein isolate & $3.595(50 \%)$ \\
\hline Carbohydrate & $48.25 \mathrm{~g}$ (fiber $2.99 \mathrm{~g}$ ) \\
\hline Maltodextrin & $31.3(64.88 \%)$ \\
\hline Isomaltulose & $9.97(20.66 \%)$ \\
\hline Fructose & 3.99 (8.27\%) \\
\hline Fibersol & $1.99(4.13 \%)$ \\
\hline FOS & $1.00(2.06 \%)$ \\
\hline Fat & $15.95 \mathrm{~g}$ \\
\hline Canola oil & $6.98(43.74 \%)$ \\
\hline High-oleic safflower oil & $2.99(18.77 \%)$ \\
\hline MCT oil & $5.98(37.49 \%)$ \\
\hline \multicolumn{2}{|l|}{ Micronutrient } \\
\hline \multicolumn{2}{|l|}{ Vitamins and minerals } \\
\hline Vitamin A & $67.43 \mu \mathrm{g}$ RE \\
\hline Vitamin D & $\mathrm{I} 5.20 \mathrm{IU}$ \\
\hline Vitamin C & $36.27 \mathrm{mg}$ \\
\hline Calcium & $143.6 \mathrm{mg}$ \\
\hline Phosphorus & $143.6 \mathrm{mg}$ \\
\hline Magnesium & $39.06 \mathrm{mg}$ \\
\hline Potassium & $197.4 \mathrm{mg}$ \\
\hline Sodium & $132.8 \mathrm{mg}$ \\
\hline Carnitine & $99.71 \mathrm{mg}$ \\
\hline Others & $\begin{array}{l}\text { As recommended by } \\
\text { Thailand RDI }\end{array}$ \\
\hline
\end{tabular}

Abbreviations: FOS, fructooligosaccharide; MCT, medium-chain triglyceride; $\mathrm{RE}$, retinol equivalents; IU, international units; RDI, recommended daily intake.

of potassium, and $132.8 \mathrm{mg}$ of sodium. Table 1 summarizes all the components in ORF.

All participants had their medical history reviewed. The assessment consisted of anthropometric measurements, dietary intake, and laboratory tests. Anthropometric measurements such as body weight, height, and body mass index were performed using standard protocols before and after treatment. Casual systolic blood pressure and diastolic blood pressure were measured using a standard mercury sphygmomanometer applied on the same arm after a 10-minute rest in the sitting position.

\section{Dietary intake}

All participants kept a 3-day food record and underwent dietary interviews by a registered dietitian, before and after the study period. Nutrient composition of the diets was analyzed with the Inmucal National Food Database Program. 
Daily protein intake was determined by the calculated protein equivalence of total nitrogen appearance. ${ }^{11}$

\section{Laboratory tests}

All participants underwent routine laboratory tests including assays for fasting plasma levels of glucose, total cholesterol, low-density lipoprotein, high-density lipoprotein, triglyceride, hemoglobin, creatinine, blood urea nitrogen (BUN), calcium, phosphorus, magnesium, albumin, and prealbumin at baseline, and at the end of the trial. All participants performed self-directed 24-hour urine collections and underwent creatinine clearance and urea clearance the next day, during which blood and spot urine samples were also collected. Serum and urine creatinine samples were analyzed using the enzymatic method. GFR, using the Chronic Kidney Disease Epidemiology Collaboration equation based on serum creatinine, was calculated.

\section{Safety monitoring}

Adverse events that were or were not considered to be related to ORF treatment were monitored. The patients were questioned each time in a systematic way regarding their experiences concerning adverse events during the previous week. Patients also underwent blood drawing for safety tests that included complete blood counts and liver function tests.

\section{Statistical analysis}

Data were expressed as mean \pm standard deviation, median, or number and percentage. Continuous variables between baseline and at the end of study were compared using paired $t$-tests. All statistical tests were two-sided, and $P<0.05$ was required to reject the null hypothesis. Statistical analysis was performed using SPSS for Windows, version 16.0 (SPSS, Chicago, IL, USA).

\section{Results}

Demographic data and clinical characteristics of 29 nondiabetic CKD subjects are presented in Table 2. The participants were all Thais, $75.9 \%$ male with mean age $64.9 \pm 13.3$ years. Body weight was $65.4 \pm 11.3 \mathrm{~kg}$. Mean serum albumin level was $4.4 \pm 0.3 \mathrm{~g} / \mathrm{dL}$. Mean serum creatinine and estimated GFR were $1.9 \pm 0.8 \mathrm{mg} / \mathrm{dL}$ and $37.7 \pm 12.1 \mathrm{~mL} / \mathrm{min} / 1.73 \mathrm{~m}^{2}$, respectively.

\section{Dietary intake}

Estimated energy and nutrient intake is summarized in Table 3. A significant increase in energy intake from $21.8 \pm 6.2$
Table 2 Characteristics of the study population

\begin{tabular}{ll}
\hline & $\mathbf{N}=\mathbf{2 9}$ \\
\hline Male $(\mathrm{n}, \%)$ & $22(75.86 \%)$ \\
Age (years) & $64.9 \pm 13.3$ \\
Height $(\mathrm{cm})$ & $162.6 \pm 10.1$ \\
Body weight $(\mathrm{kg})$ & $65.4 \pm \mathrm{II} .3$ \\
Body mass index $\left(\mathrm{kg} / \mathrm{cm}^{2}\right)$ & $24.7 \pm 2.8$ \\
Systolic blood pressure $(\mathrm{mmHg})$ & $133.3 \pm 14.3$ \\
Diastolic blood pressure $(\mathrm{mmHg})$ & $75.9 \pm 11.1$ \\
Hemoglobin $(\mathrm{g} / \mathrm{dL})$ & $13.0 \pm 1.7$ \\
Prealbumin $(\mathrm{mg} / \mathrm{dL})$ & $35.7 \pm 6.7$ \\
Albumin $(\mathrm{g} / \mathrm{dL})$ & $4.4 \pm 0.3$ \\
AST $(\mathrm{U} / \mathrm{L})$ & $23.1 \pm 9.1$ \\
ALT $(\mathrm{U} / \mathrm{L})$ & $19.8 \pm 10.2$ \\
ALP $(\mathrm{U} / \mathrm{L})$ & $72.0 \pm 23.9$ \\
BUN $(\mathrm{mg} / \mathrm{dL})$ & $25.9 \pm 15.1$ \\
Serum creatinine $(\mathrm{mg} / \mathrm{dL})$ & $1.9 \pm 0.8$ \\
CKD-EPI $\left(\mathrm{mL} / \mathrm{min} / \mathrm{l} .73 \mathrm{~m}^{2}\right)$ & $37.7 \pm 12.1$ \\
\hline
\end{tabular}

Note: Values are presented as $n(\%)$ and mean \pm SD.

Abbreviations: AST, aspartate aminotransferase; ALT, alanine aminotransferase; ALP, alkaline phosphatase; BUN, blood urea nitrogen; CKD-EPI, Chronic Kidney Disease Epidemiology Collaboration; SD, standard deviation.

to $23.3 \pm 5.6 \mathrm{kcal} / \mathrm{kg} /$ day was noted during the study $(P=0.044)$. At the end of the study, dietary intake of fat and fiber increased significantly by $8.98 \pm 11.54 \mathrm{kcal} /$ day $(P<0.001)$ and $2.32 \pm 3.88 \mathrm{~g} /$ day $(P=0.003)$, respectively. Additionally, calcium intake (349.6 \pm 150.3 versus $454.7 \pm 154.2 ; P=0.016)$ and magnesium intake $(36.0 \pm 17.5$ versus $71.6 \pm 28.0$; $P=0.001$ ) improved after 1 week of intervention. However, dietary protein intake significantly decreased from $0.9 \pm 0.3$ to $0.8 \pm 0.2 \mathrm{~g} / \mathrm{kg} /$ day $(P=0.036)$. No significant change was found in other serum electrolytes including sodium, potassium, and phosphorus after intervention.

\section{Nutritional and metabolic parameters}

Nutritional and metabolic biomarkers during the period of the study are summarized in Table 4. Overall, nutritional biomarkers including body weight, prealbumin, albumin, and protein equivalence of total nitrogen appearance did not significantly change during the 1 -week baseline period. Similarly, metabolic profiles including fasting plasma glucose, lipid profiles, and hemoglobin did not significantly change.

\section{Biochemical and renal function measurement}

At the end of the study, BUN decreased significantly by $-1.90 \pm 4.95 \mathrm{mg} / \mathrm{dL}(P=0.048)$, and serum magnesium increased significantly by $0.08 \pm 0.16 \mathrm{mg} / \mathrm{dL}(P=0.015)$. The treatment did not significantly change the levels of serum 
Table 3 Dietary intake with 3-day food record at baseline and at the end of I-week follow-up

\begin{tabular}{|c|c|c|c|c|}
\hline Per day & Baseline & End & Mean change $(95 \% \mathrm{Cl})$ & $P$-value \\
\hline Energy (kcal) & $1,394.1 \pm 342.1$ & $1,495.4 \pm 339.9$ & $101.38(9.60,193.20)$ & 0.032 \\
\hline Energy (kcal/kg/day) & $21.8 \pm 6.2$ & $23.3 \pm 5.6$ & $\mathrm{I} .44(0.0 \mathrm{I}, 2.84)$ & 0.044 \\
\hline Protein $(g)$ & $58.1 \pm 22.2$ & $50.9 \pm 14.5$ & $-7.16(-14,-0.37)$ & 0.040 \\
\hline Protein (g/kg/day) & $0.9 \pm 0.3$ & $0.8 \pm 0.2$ & $-0.12(-0.20,-0.01)$ & 0.036 \\
\hline Carbohydrate (g) & $200.6 \pm 58.1$ & $222.1 \pm 64.9$ & $21.50(-2.20,45.21)$ & 0.074 \\
\hline Fat $(g)$ & $39.3 \pm 13.4$ & $48.3 \pm 13.4$ & $8.98(4.60,13.37)$ & 0.001 \\
\hline Fiber $(g)$ & $8.0 \pm 4.2$ & $10.4 \pm 3.8$ & $2.32(0.80,3.80)$ & 0.003 \\
\hline Sodium (mg) & I,934.4 \pm 699.1 & $2,|I| 1.7 \pm 843.6$ & $|77.2|(-\mid 70,524.47)$ & 0.305 \\
\hline Potassium (mg) & $1,223.6 \pm 407.0$ & $1,192.3 \pm 364.2$ & $-31.35(-188.70,126.01)$ & 0.686 \\
\hline Calcium (mg) & $349.6 \pm 150.3$ & $454.7 \pm 154.2$ & $104.50(21.30,187.73)$ & 0.016 \\
\hline Phosphorus (mg) & $621.1 \pm 164.4$ & $636.0 \pm 168.9$ & $14.90(-39.90,69.68)$ & $0.58 \mathrm{I}$ \\
\hline Magnesium (mg) & $36.0 \pm 17.5$ & $71.6 \pm 28.0$ & $35.50(25.60,45.39)$ & 0.001 \\
\hline
\end{tabular}

Notes: Values are presented as mean \pm SD and mean change $(95 \% \mathrm{Cl})$. $P$-value corresponds to paired $t$-test.

Abbreviations: $\mathrm{Cl}$, confidence interval; $\mathrm{SD}$, standard deviation.

Table 4 Nutritional and laboratory parameters at baseline and at the end of I-week follow-up

\begin{tabular}{|c|c|c|c|c|}
\hline Variables & Baseline & End & $\begin{array}{l}\text { Mean change } \\
(95 \% \mathrm{Cl})\end{array}$ & $P$-value \\
\hline \multicolumn{5}{|l|}{ Nutrition parameters } \\
\hline Body weight (kg) & $65.6 \pm 11.2$ & $65.5 \pm \mathrm{II} .4$ & $-0.03(-0.40,0.36)$ & 0.869 \\
\hline Serum albumin (g/dL) & $4.4 \pm 0.3$ & $4.4 \pm 0.3$ & $0.04(-0.10,0.13)$ & 0.392 \\
\hline Prealbumin (mg/dL) & $35.7 \pm 6.7$ & $36.3 \pm 8.2$ & $0.56(-1.60,2.68)$ & 0.592 \\
\hline nPNA (g/kg/day) & $0.9 \pm 0.3$ & $0.8 \pm 0.3$ & $-0.07(-0.20,0.02)$ & 0.122 \\
\hline \multicolumn{5}{|l|}{ Metabolic parameters } \\
\hline Systolic BP (mmHg) & $130.5 \pm|7|$. & $130.2 \pm 15.2$ & $-0.28(-4.70,4.09)$ & 0.898 \\
\hline Diastolic BP (mmHg) & $73.7 \pm 12.1$ & $74.5 \pm 10.7$ & $0.86(-1.70,3.46)$ & 0.502 \\
\hline Hemoglobin (g/dL) & $13.0 \pm 1.7$ & $12.8 \pm 1.5$ & $-0.08(-0.20,0.08)$ & 0.303 \\
\hline FPG (mg/dL) & $95 \pm 11.9$ & $94.1 \pm 12.0$ & $-0.86(-3.10,1.41)$ & 0.443 \\
\hline Total bilirubin (mg/dL) & $0.5 \pm 0.2$ & $0.5 \pm 0.2$ & $-0.03(-0.10,0.02)$ & 0.143 \\
\hline AST (U/L) & $21.8 \pm 7.9$ & $21.2 \pm 7.4$ & $-0.55(-1.50,0.37)$ & 0.229 \\
\hline ALT (U/L) & $19.2 \pm 7.3$ & $18.6 \pm 6.8$ & $-0.69(-2.30,0.96)$ & 0.398 \\
\hline ALP (U/L) & $71.8 \pm 22.3$ & $70.7 \pm 27.1$ & $-1.10(-6.30,4.11)$ & 0.668 \\
\hline \multicolumn{5}{|c|}{ Serum electrolytes, mineral, and renal parameters } \\
\hline BUN (mg/dL) & $25.9 \pm 15.1$ & $23.9 \pm 14.4$ & $-1.90(-3.80,-0.02)$ & 0.048 \\
\hline Serum creatinine (mg/dL) & $1.9 \pm 0.9$ & $2.3 \pm 1.9$ & $0.34(-0.40,1.06)$ & 0.337 \\
\hline Estimated GFR $\left(\mathrm{mL} / \mathrm{min} / \mathrm{l} .73 \mathrm{~m}^{2}\right)$ & $38.9 \pm 13.8$ & $36.9 \pm 14.3$ & $-2.03(-5.90,1.85)$ & 0.292 \\
\hline Sodium (mEq/L) & $140.3 \pm 2.3$ & $140.4 \pm 2.3$ & $0.09(-0.60,0.74)$ & 0.772 \\
\hline Potassium (mEq/L) & $4.4 \pm 0.4$ & $4.6 \pm 0.4$ & $0.05(-0.10,0.17)$ & 0.437 \\
\hline Chloride (mEq/L) & $102.2 \pm 3.8$ & $102.1 \pm 3.6$ & $-0.15(-1.10,0.8)$ & 0.747 \\
\hline Bicarbonate (mg/dL) & $23.7 \pm 3.3$ & $24.1 \pm 3.2$ & $0.37(-0.30,1.03)$ & 0.258 \\
\hline Calcium (mg/dL) & $9.2 \pm 0.4$ & $9.3 \pm 0.4$ & $0.06(-0.10,0.21)$ & 0.442 \\
\hline Phosphorus (mg/dL) & $3.4 \pm 0.6$ & $3.5 \pm 0.6$ & $0.08(-0.10,0.27)$ & 0.391 \\
\hline Magnesium (mg/dL) & $2.1 \pm 0.2$ & $2.2 \pm 0.3$ & $0.08(0.01,0.14)$ & 0.015 \\
\hline \multicolumn{5}{|c|}{ 24-hour urine electrolytes and clearance } \\
\hline Sodium (mEq/day) & $29.7 \pm 9.5$ & $32.7 \pm 12.5$ & $3.03(-2.20,8.26)$ & 0.245 \\
\hline Protein (g/day) & $0.6 \pm 1.3$ & $0.5 \pm 0.7$ & $-0.11(-0.40,0.17)$ & 0.419 \\
\hline Urea clearance (mL/min) & $21.9 \pm 9.5$ & $23.3 \pm 13.6$ & $0.49(-5.20,6.17)$ & 0.860 \\
\hline Creatinine clearance $(\mathrm{mL} / \mathrm{min})$ & $48.3 \pm 18.4$ & $48.8 \pm 25.3$ & $1.32(-1.60,4.20)$ & 0.355 \\
\hline
\end{tabular}

Notes: Values are presented as mean \pm SD and mean change $(95 \% \mathrm{Cl})$. $P$-value corresponds to paired $t$-test.

Abbreviations: $\mathrm{Cl}$, confidence interval; nPNA, protein equivalence of total nitrogen appearance; $\mathrm{BP}$, blood pressure; FPG, fasting plasma glucose; AST, aspartate aminotransferase; ALT, alanine aminotransferase; ALP, alkaline phosphatase; BUN, blood urea nitrogen; GFR, glomerular filtration rate; SD, standard deviation. 
creatinine, estimated GFR, sodium, potassium, bicarbonate, phosphorus, magnesium, urea clearance, and creatinine clearance.

\section{Safety profile}

During the study period, no major complications and gastrointestinal adverse effects were observed. The rate of adverse events with hyperkalemia (potassium $>5.5 \mathrm{mEq} / \mathrm{L}$ ), hypercalcemia (calcium $>10.5 \mathrm{mg} / \mathrm{dL}$ ), hyperphosphatemia (phosphorus $>5.5 \mathrm{mg} / \mathrm{dL}$ ), and elevated liver enzymes among patients given dietary supplement was not detected. At the study's completion, all subjects expressed a desire to continue receiving the ORS supplementation.

\section{Discussion}

The present study constitutes the first clinical trial of ORF in CKD patients. The supplement increased energy, fat, and fiber intake and decreased protein intake without changing the serum minerals and electrolytes in a predialysis CKD population. Thus, ORF supplement tends to benefit the predialysis CKD population. However, the finding is a short-term clinical outcome.

Nutritional intervention among predialysis CKD patients is often complicated and costly. Limited evidence exists pertaining to the impact of individualized nutritional intervention by a renal dietitian on clinical outcomes among patients with CKD. ${ }^{12}$ Based on the Kidney Disease Outcomes Quality Initiative Clinical Practice Guidelines in CKD, adults with CKD stage III-IV are recommended a diet with adequate energy to maintain desirable body weight and normal protein near the level of $0.6-0.8 \mathrm{~g} / \mathrm{kg} /$ day. ${ }^{13}$ In addition, the European Society for Clinical Nutrition and Metabolism guidelines recommend that oral nutritional supplements and tube feeding offer the possibility of increasing nutrient intake in patients with inadequate dialysis and restrict protein intake at $0.55-0.6 \mathrm{~g} / \mathrm{kg} /$ day in predialysis CKD cases. ${ }^{14}$ Our findings revealed that ORF could significantly improve energy and fiber intake and maintain nutritional markers among wellnourished CKD patients with advanced age and normal body mass index. Studies with low-protein diet and oral essential nutrient supplements have reported similar findings. After short- and long-term follow-up, the treatment appears to confirm a maintained nutrition status with a significantly slow CKD progression. ${ }^{15,16}$ Similarly, for patients on maintenance hemodialysis, oral nutritional supplement given during hemodialysis improved nutritional markers among malnourished dialysis patients. ${ }^{17}$ Further studies of the efficacy of ORF regimen with respect to improving clinical outcomes are required regarding malnourished CKD patients.

A recent meta-analysis study evaluating dietary protein intake in a CKD population showed that dietary protein restriction reduced the rate of decline in estimated GFR. ${ }^{18}$ However, a subsequently published Cochrane review study evaluating dietary protein restriction found no significant dietary protein restriction on CKD progression. ${ }^{19}$ Our findings revealed that ORF significantly reduced protein intake to $0.8 \mathrm{~g} / \mathrm{kg}$ /day with a lower BUN level and maintained nutritional markers among CKD patients. Additionally, several studies have investigated the beneficial effects of severe hypoproteic diet supplemented with ketoanalogs in advanced CKD patients in a placebo-controlled randomized prospective study. As in our study, their treatments improved nitrogen waste products retention and maintained nutritional status in patients with CKD. ${ }^{20,21}$

Restrictions of dietary components are often implemented in CKD patients because of an increased risk of uremia, salt retention, hyperkalemia, hyperphosphatemia, negative calcium balance, and metabolic acidosis. ${ }^{22}$ The Kidney Disease Outcomes Quality Initiative and Kidney Disease: Improving Global Outcomes guidelines recommend that individuals with $\mathrm{CKD}$ receive appropriate dietary advice, tailored to the severity of CKD and the need to intervene on dietary sodium ( $<90 \mathrm{mEq} /$ day or $<2 \mathrm{~g} /$ day), potassium (2-4 g/day), and phosphorus (0.8-1.0 g/day) restriction where indicated. ${ }^{13,23}$ Our findings revealed that ORF supplement could achieve the therapeutic targets of dietary intake with an average dietary sodium intake of $2.1 \mathrm{~g} /$ day, average 24 -hour urine sodium of $34 \mathrm{mEq} /$ day, average dietary potassium intake of $1.1 \mathrm{~g} /$ day, and average dietary phosphorus intake of $0.6 \mathrm{~g} /$ day. Most importantly, ORF supplement did not disturb serum minerals and electrolyte levels among CKD patients. In contrast, ORF supplement could improve dietary calcium and magnesium intake and serum magnesium levels.

The study had a few limitations. First, the study design was not randomized or placebo-controlled. Second, a selection bias of subjects might exist. Our subjects were mainly the army population and their spouses. This might be one reason why more men than women participated. Third, our study had a short duration of ORF administration and a relatively small number of enrolled patients. Long-term compliance, safety, and efficacy of this diet regimen with respect to improving clinical outcomes require further study.

In conclusion, this prospective study indicated that consuming special renal nutritional formula produces more 
energy, fiber, trace elements intake, and less protein intake in predialytic CKD patients. This supplementation might provide a palatable and practical treatment. However, its clinical impact and effectiveness should be further assessed in a larger group of patients over a longer period.

\section{Acknowledgment}

This work was supported by a grant from Phramongkutklao Hospital and College of Medicine, Bangkok, Thailand.

\section{Disclosure}

The authors report no conflicts of interest in this work.

\section{References}

1. Kovesdy CP, George SM, Anderson JE, Kalantar-Zadeh K. Outcome predictability of biomarkers of protein-energy wasting and inflammation in moderate and advanced chronic kidney disease. Am J Clin Nutr. 2009;90(2):407-414.

2. Lawson JA, Lazarus R, Kelly JJ. Prevalence and prognostic significance of malnutrition in chronic renal insufficiency. J Ren Nutr. 2001;11(1):16-22.

3. Kopple JD, Berg R, Houser H, Steinman TI, Teschan P. Nutritional status of patients with different levels of chronic renal insufficiency. Modification of Diet in Renal Disease (MDRD) Study Group. Kidney Int Suppl. 1989;27:S184-S194.

4. Campbell KL, Ash S, Davies PS, Bauer JD. Randomized controlled trial of nutritional counseling on body composition and dietary intake in severe CKD. Am J Kidney Dis. 2008;51(5):748-758.

5. Kovesdy CP, Kopple JD, Kalantar-Zadeh K. Management of proteinenergy wasting in non-dialysis-dependent chronic kidney disease: reconciling low protein intake with nutritional therapy. Am J Clin Nutr. 2013;97(6):1163-1177.

6. Satirapoj B, Supasyndh O, Mayteedol N, et al. Obesity and its relation to chronic kidney disease: a population-based, cross-sectional study of a Thai army population and relatives. Nephrology (Carlton). 2013;18(3):229-234.

7. Satirapoj B. Nephropathy in diabetes. Adv Exp Med Biol. 2012;771: 107-122.

8. Dukkipati R, Kopple JD. Causes and prevention of protein-energy wasting in chronic kidney failure. Semin Nephrol. 2009;29(1):39-49.

9. Supasyndh O, Satirapoj B, Seenamngoen S, Yongsiri S, Choovichian P, Vanichakarn S. Nutritional status of twice and thrice-weekly hemodialysis patients with weekly Kt/V > 3.6. J Med Assoc Thai. 2009;92(5): 624-631.
10. Cano N, Fiaccadori E, Tesinsky P, et al. ESPEN Guidelines on Enteral Nutrition: adult renal failure. Clin Nutr. 2006;25(2):295-310.

11. Clinical practice guidelines for nutrition in chronic renal failure. K/DOQI, National Kidney Foundation. Am J Kidney Dis. 2000; 35(6 Suppl 2):S1-S140.

12. Campbell KL, Ash S, Zabel R, McFarlane C, Juffs P, Bauer JD. Implementation of standardized nutrition guidelines by renal dietitians is associated with improved nutrition status. J Ren Nutr. 2009;19(2):136-144.

13. Kidney Disease Outcomes Quality Initiative (K/DOQI). K/DOQI clinical practice guidelines on hypertension and antihypertensive agents in chronic kidney disease. Am J Kidney Dis. 2004;43(5 Suppl 1): S1-S290.

14. Cano NJ, Aparicio M, Brunori G, et al. ESPEN Guidelines on Parenteral Nutrition: adult renal failure. Clin Nutr. 2009;28(4):401-414.

15. Chang JH, Kim DK, Park JT, et al. Influence of ketoanalogs supplementation on the progression in chronic kidney disease patients who had training on low-protein diet. Nephrology (Carlton). 2009;14(8): 750-757.

16. Teplan V, Schuck O, Knotek A, et al. Effects of low-protein diet supplemented with ketoacids and erythropoietin in chronic renal failure: a long-term metabolic study. Ann Transplant. 2001;6(1):47-53.

17. Caglar K, Fedje L, Dimmitt R, Hakim RM, Shyr Y, Ikizler TA. Therapeutic effects of oral nutritional supplementation during hemodialysis. Kidney Int. 2002;62(3):1054-1059.

18. Kasiske BL, Lakatua JD, Ma JZ, Louis TA. A meta-analysis of the effects of dietary protein restriction on the rate of decline in renal function. Am J Kidney Dis. 1998;31(6):954-961.

19. Robertson L, Waugh N, Robertson A. Protein restriction for diabetic renal disease. Cochrane Database Syst Rev. 2007;(4):CD002181.

20. Mircescu G, Garneata L, Stancu SH, Capusa C. Effects of a supplemented hypoproteic diet in chronic kidney disease. J Ren Nutr. 2007;17(3):179-188.

21. Prakash S, Pande DP, Sharma S, Sharma D, Bal CS, Kulkarni H. Randomized, double-blind, placebo-controlled trial to evaluate efficacy of ketodiet in predialytic chronic renal failure. J Ren Nutr. 2004;14(2):89-96.

22. Fouque D. Why is the diet intervention so critical during chronic kidney disease? J Ren Nutr. 2003;13(3):173.

23. Stevens PE, Levin A; Kidney Disease: Improving Global Outcomes Chronic Kidney Disease Guideline Development Work Group Members. Evaluation and management of chronic kidney disease: synopsis of the kidney disease: improving global outcomes 2012 clinical practice guideline. Ann Intern Med. 2013;158(11):825-830.

\section{Publish your work in this journal}

The International Journal of Nephrology and Renovascular Disease is an international, peer-reviewed open-access journal focusing on the pathophysiology of the kidney and vascular supply. Epidemiology, screening, diagnosis, and treatment interventions are covered as well as basic science, biochemical and immunological studies. The journal welcomes original research, clinical studies, reviews \& evaluations, expert opinion and commentary, case reports and extended reports. The manuscript management system is completely online and includes a very quick and fair peerreview system, which is all easy to use. Visit http://www.dovepress.com/ testimonials.php to read real quotes from published authors. 